\title{
The Structural and Electrical Properties of Nanostructures ZnO Thin Films on Flexible Substrate
}

\author{
Nur Sa'adah Muhamad Sauki ${ }^{\#}$, Nur Amalina Muhamad", Fazlinashatul Suhaidah Zahid ${ }^{\#}$, Sukreen Hana \\ Herman $^{*}$, Zairi Ismael Rizman ${ }^{\#}$ \\ ${ }^{\#}$ Faculty of Electrical Engineering, Universiti Teknologi MARA, 81750 Masai, Johor, Malaysia \\ E-mail: saadah1537@johor.uitm.edu.my, amalina0942@johor.uitm.edu.my,fazlina7803@johor.uitm.edu.my
}

${ }^{*}$ NANO-ElecTronic Centre, Faculty of Electrical Engineering, Universiti Teknologi MARA, 40450 Shah Alam, Selangor, Malaysia E-mail: hana1617@salam.uitm.edu.my

${ }^{\#}$ Faculty of Electrical Engineering, Universiti Teknologi MARA, 23000 Dungun, Terengganu, Malaysia

E-mail: zairi576@tganu.uitm.edu.my

\begin{abstract}
Zinc oxide (ZnO) thin films were deposited on Teflon substrates by radio frequency (RF) magnetron sputtering method at different substrate temperature. The dependence of residual stress on the substrate temperature was investigated in this work due to the growth process, the bombardment of energetic particles and process heating to the deposited thin films. From field emission scanning electron microscope (FESEM) images, samples that deposited at various substrate temperatures consists nano-sized particles. The obtained $\mathrm{X}$-ray diffraction (XRD) results, it suggested that $\mathrm{ZnO}$ thin film deposited at $40^{\circ} \mathrm{C}$ with highly c-axis oriented shows unstressed film compared to other thin films. Besides that, the $\mathrm{ZnO}$ thin films deposited at $40^{\circ} \mathrm{C}$ shows improved electrical properties.
\end{abstract}

Keywords - ZnO thin films; substrate temperatures; Teflon substrate; RF magnetron sputtering

\section{INTRODUCTION}

Research on a flexible substrate has been attracting much attention nowadays due to its attractive properties such as light weight and high resistance to impact damage. These properties make them suited for the fabrication of electronic device. Due to the poor thermal endurance of flexible substrate, zinc oxide $(\mathrm{ZnO})$ is one of the materials that can be grown at lower deposition temperatures [1]. $\mathrm{ZnO}$ is naturally n-type direct band gap semiconductor materials that possess some great characteristics which are wide energy band gap, $3.37 \mathrm{eV}$ at room temperature and large free exciton binding energy, $60 \mathrm{meV}$. It has the hexagonal crystalline structure of the wurtzite type and unit cell with a constant $a=3.24 \AA$ and $c=5.19 \AA$ as shown in Fig. 1 .

Few flexible substrates found in literature such as polyethylene naphthalate (PEN), polyethylene terephthalate (PET), polycarbonate (PC) and polyethersulfone (PES) [3][6]. However, there is a lack of paper on growing $\mathrm{ZnO}$ thin films on polytetrafluoroethylene (Teflon) [7]. We choose polytetrafluoroethylene (Teflon) for our flexible substrates. The properties of Teflon make it a suitable choice for many

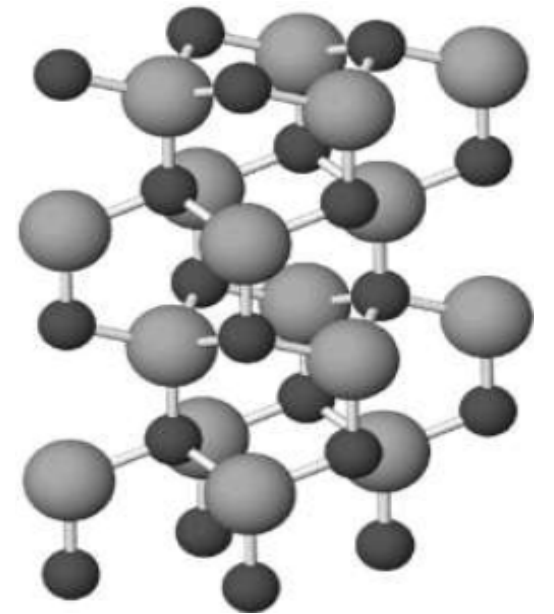

Fig. 1 Wurtzite structure of $\mathrm{ZnO}$. Big and small spheres denote oxygen and zinc atoms respectively [2]

microelectronic applications. These are low chemical reactivity, high melting point $\left(\sim 327^{\circ} \mathrm{C}\right)$ and low coefficient friction $(0.05$ to 0.10$)$ make it suitable choice for many microelectronic applications. Furthermore, Teflon has high 
surface resistivity and high dielectric strength which means that the voltage that Teflon can withstand before it breaks down is high. In addition, Teflon has a low dissipation factor which is the percentage of electrical energy absorbed and lost when current is applied. A low dissipation factor indicates that the absorbed energy dissipated as heat is low. The high surface resistivity indicates the electrical resistance between opposite edges of a unit square on the surface of an insulating material. In this work, Teflon is chosen to be the substrate due to the availability in the market besides the above said favorable properties. Apart from that, Teflon can withstand corrosive environments and has a low dissipation factor.

The sputtering method is a process where atoms are ejected from a solid target material due to the bombardment of the target by energetic particles. There are a few steps to make a thin film using the sputtering method. The first step is to place substrate material in a vacuum chamber. Then, the air is removed, and the target material that desired to be deposited is released in the form of gas. The particle is bombarded with the energetic ions, inert gas ions (Ar+) typically. In the form of Ar+ 10 plasma, the negatively charged target material lines up on the substrate to form a thin film. Thin films can range in thickness from a few atoms to a few hundred atoms or molecules, which depend on the sputtering time [8]. It only happens when the kinetic energy of the incoming particles is much higher than conventional thermal energies. Sputtered atoms ejected from the target have a wide energy distribution, typically up to tens of eV $(100,000 \mathrm{~K})$ as can be seen in Fig. 2. The sputtered ions ejected from the target in straight lines and impact energetically on the substrates or vacuum chamber (causing resputtering) [9].

In this work, we choose RF magnetron sputtering as our method in order to deposit $\mathrm{ZnO}$ thin films on Teflon substrates.

Radio frequency (RF) magnetron sputtering method is used to deposit $\mathrm{ZnO}$ thin films on flexible due to its advantages ability to produce a uniform thin film which is good in adhesion and highly crystalline. In this paper, we report on the use of RF magnetron sputtering as a method in order to deposit a $\mathrm{ZnO}$ thin film on the flexible substrate at different substrate temperature for fabrication of high (002) oriented films. Apart from that, the residual stress was calculated in order to investigate the effect of the substrate deformation due to the growth process, the bombardment of energetic particles and process heating to the deposited thin films.

The flexible substrates technologies have recently attracted tremendous interest for the development of highlydemanding future product applications in efficient portable devices which are lightweight, foldable and wearable. However, there are some problems that need to be considered in the fabrication of the devices such as:

- The issue of obtaining high-quality thin films on polymer substrate at lower temperature (to suit poor thermal endurance of flexible substrates)

- Optimization of the deposition condition must be carried out to produce high-quality $\mathrm{ZnO}$ thin film
In this work, we focused on the growth of $\mathrm{ZnO}$ on Teflon substrate by using RF magnetron sputtering.

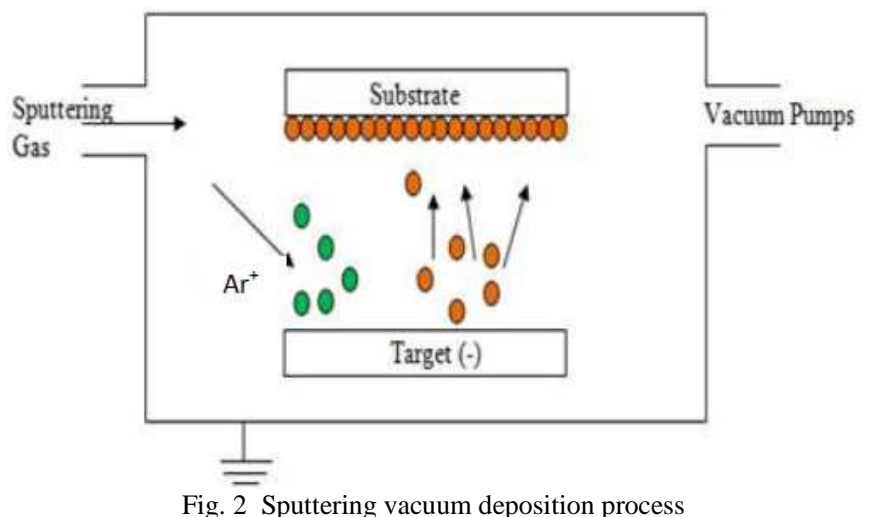

\section{MATERIAL AND METHOD}

The deposition of $\mathrm{ZnO}$ film on Teflon substrate by RF magnetron sputtering methods and the characterization techniques that were used in this work are described in this section.

There are three steps in order to deposit $\mathrm{ZnO}$ thin films on Teflon substrate. The first step is the cleaning substrates, followed by deposition $\mathrm{ZnO}$ thin films and third steps are to material characterizations.

\section{A. Teflon Substrates Cleaning Technique}

Substrate cleaning technique is one of most important step in order to produce high-quality $\mathrm{ZnO}$ thin films. It is important to remove any organic and inorganic contamination on the substrate, prior to the deposition process. Contamination on the substrate may disturb the crystal growth and also negatively affect the performance of the fabricated device.

The Teflon substrates were cleaned by acetone in the ultrasonic cleaner for 10 minutes and followed by methanol for another 10 minutes in the ultrasonic cleaner. Then, the substrates were rinsed with deionized water (DI) in the ultrasonic cleaner for 10 minutes. Fig. 3 shows the flow of cleaning process.

Ultrasonic cleaner was used to clean Teflon substrates using acetone for about $10 \mathrm{~min}$

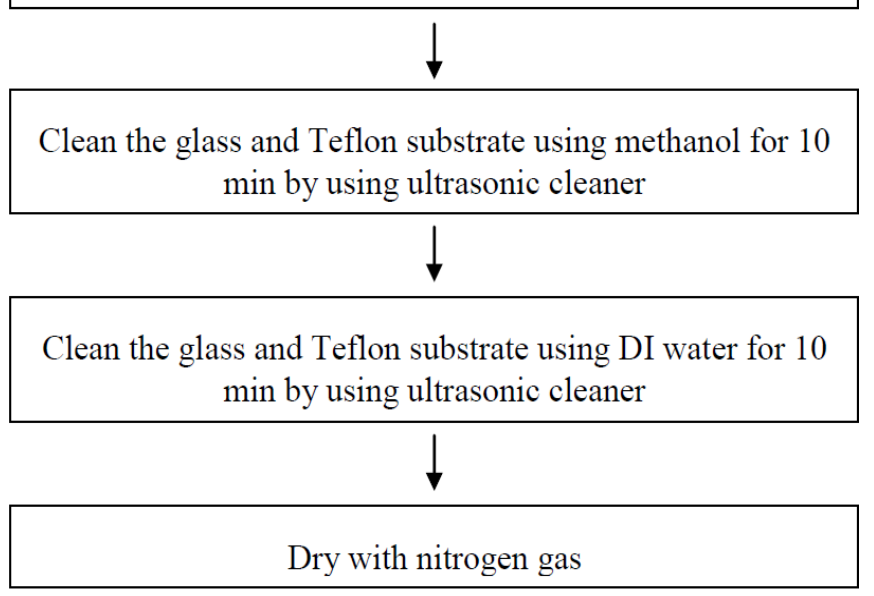

Fig. 3 Flow chart of cleaning process 
Process chamber

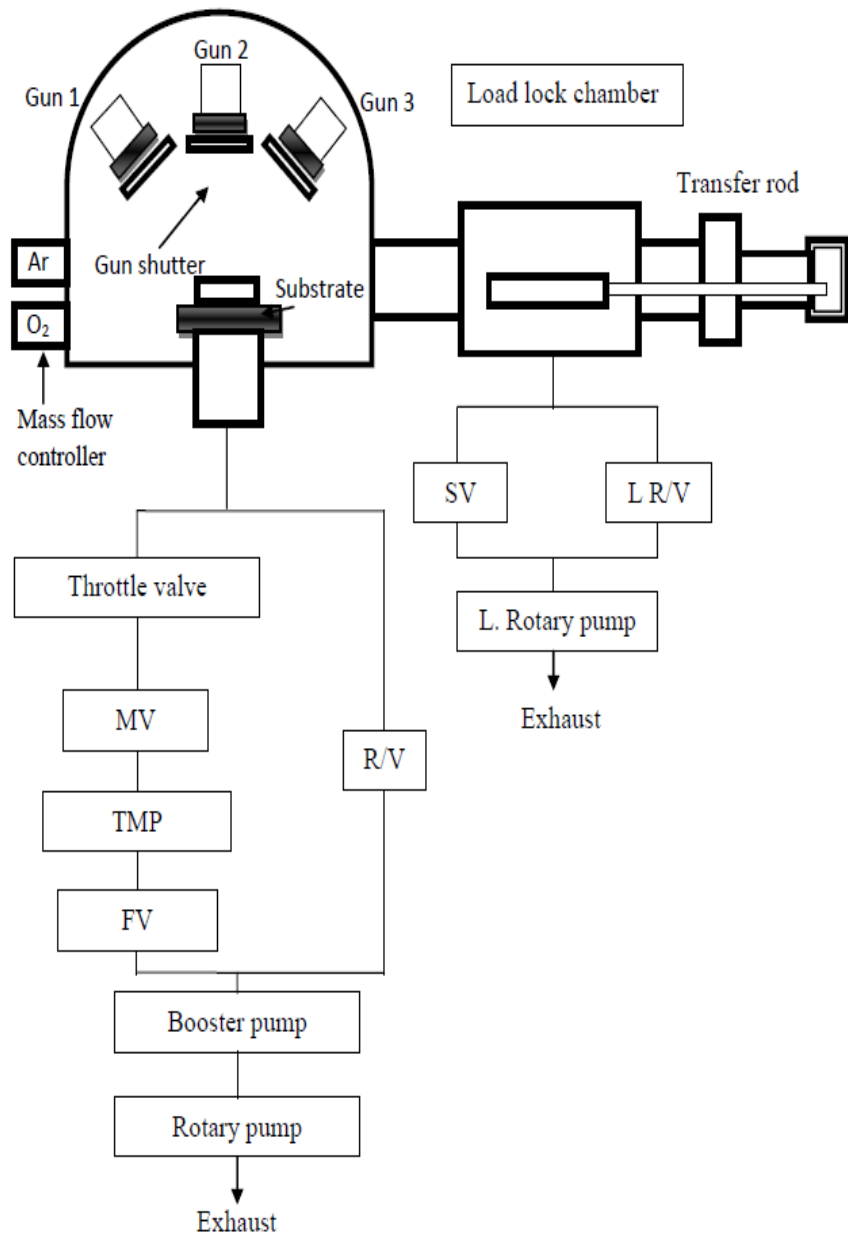

Fig. 4 Schematic diagram of the RF magnetron sputtering system

The deposition process was done by using RF magnetron sputtering (RSP-5004 (10SN06)). ZnO was deposited on polytetrafluoroethylene (Teflon) substrate using 4-inch in diameter $99.99 \% \mathrm{ZnO}$ as the target. The details preparation, the background pressure in the sputtering chamber is $3.75 \times 10^{-}$Torr, the working pressure was maintained at $5 \mathrm{mT}$ Torr. For the first deposition, the samples were deposited for 1-hour deposition at different substrate temperatures, room temperature, $40^{\circ} \mathrm{C}$, and $60^{\circ} \mathrm{C}$. Table 1 shows the sputtering used in this work and Fig. 4 shows the schematic diagram of the RF magnetron sputtering system that was used in this work.

TABLE I

PARAMETERS OF DEPOSITION ZNO FILMS ON TEFLON SUBSTRATE OF RF MAGNETRON SPUTTERING

\begin{tabular}{|l|l|}
\hline Background Pressure & $\sim 10^{-7}$ mTorr \\
\hline Target & $\mathrm{ZnO}$ \\
\hline Substrate Temperature $\left({ }^{\mathbf{0}} \mathbf{C}\right)$ & unheated, $40^{\circ} \mathrm{C}, 60^{\circ} \mathrm{C}$ \\
\hline Ar $($ sccm) & 45 \\
\hline O2 (sccm) & 0 \\
\hline Sputtering Pressure (mTorr) & 5 \\
\hline Process Time (sec) & 1 hour \\
\hline
\end{tabular}

\section{Characterizations of $\mathrm{ZnO}$ Thin Films}

The characterizations are divided into two parts, which are structural and electrical properties.

\section{Structural Properties}

The structural properties were characterized by using the field-effect scanning electron microscope (FESEM) and the X-ray diffraction (XRD-Rigaku Ultima IV) used for the surface morphology and crystallinity properties respectively.

\section{E. Surface Morphology}

Surface morphology of the deposited $\mathrm{ZnO}$ thin films was measured using FESEM. The SEM image gives information of the thin film morphology and also the particle size of the thin film. Table 2 shows the parameters during the characterization.

TABLE III

FESEM CHARACTERIZATION PARAMETERS

\begin{tabular}{|l|l|}
\hline Magnification & $80000-100000$ \\
\hline Scale & $100 \mathrm{~nm}$ \\
\hline Power & $2 \mathrm{kV}$ \\
\hline
\end{tabular}

\section{F. Crystallinity}

$\mathrm{X}$-ray diffraction (XRD) is a versatile, non-destructive technique that reveals detailed information about the crystallographic structure of deposited thin film. When a monochromatic X-ray beam with wavelength, $\lambda$, is projected onto a crystalline material at an angle, $\theta$, diffraction occurs only when the distance traveled by the rays reflected from successive planes differs by a complete number $n$ of wavelengths as can be seen in Fig. 5.

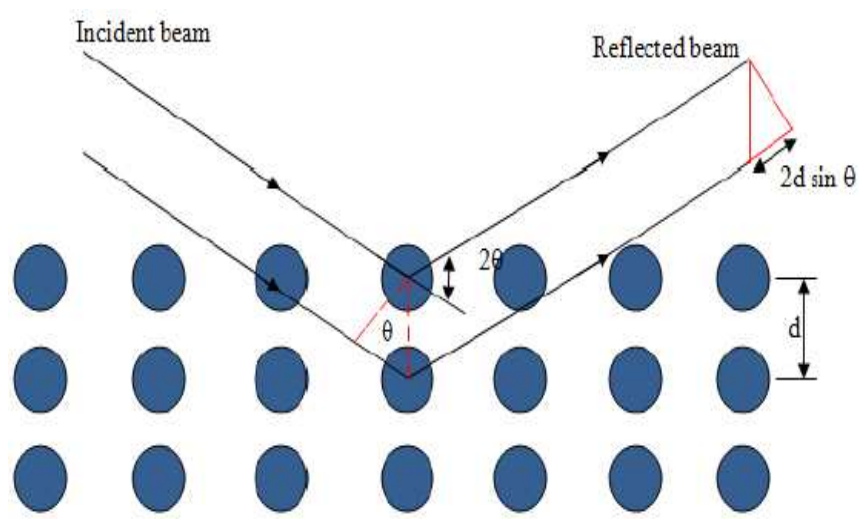

Fig. 5 Bragg's law

Bragg's Law refers to the simple equation as follows

$$
\mathrm{n} \lambda=2 \mathrm{~d} \sin \theta
$$

By varying the angle $\theta$, the Bragg's Law conditions are satisfied by different $d$-spacing in polycrystalline materials. Plotting the angular positions and intensities of the resultant diffracted peaks of radiation produces a pattern, which is characteristic of the sample. When a mixture of different phases is present, the resultant diffractogram is formed by the addition of the individual patterns. Based on the principle of X-ray diffraction, a wealth of structural and physical information about the material investigated can be obtained. 
From the XRD collection data, the crystallite size can be calculated using Scherrer's equation as follows

$$
D=\frac{K \lambda}{B \cos \theta}
$$

where $\mathrm{D}$ is the crystallite size, $\mathrm{K}$ is a constant value 0.9 which depends mainly on the crystalline shape and indices,

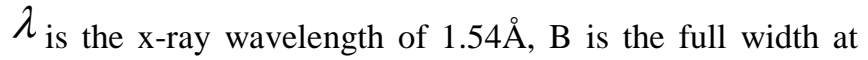
half maximum of the (002) plane wavelength in radian from XRD data, $\theta$ is the Bragg's angle in degrees [10]. Apart from that, the stress can be calculated using biaxial strain model as follows [11]

$$
\partial_{f i l m}=\frac{2\left(c_{13}\right)^{2}-c_{33}\left(c_{11}+c_{12}\right)}{2 c_{13}} * \varepsilon_{z z}
$$

where the elastics constant $\mathrm{C}_{\mathrm{ij}}$, data of single-crystalline $\mathrm{ZnO}$ have been used, $\mathrm{C}_{11}=208.8 \mathrm{GPa}, \mathrm{C}_{12}=119.7 \mathrm{GPa}, \mathrm{C}_{13}=$ $213.8 \mathrm{GPa}, \varepsilon_{\mathrm{zz}}$ is the strain of the thin film. This yields the following numerical relation for the stress derived from XRD: $\sigma_{\text {film }}=-233 \varepsilon_{\mathrm{zz}}$. The strain $\left(\varepsilon_{\mathrm{zz}}\right)$ values can be calculated using equation as follows [12]

$$
\varepsilon_{z z}=\frac{c_{f i l m}-c}{c}
$$

where $\mathrm{C}$ is the unstrained lattice constant of $\mathrm{ZnO}, 5.206 \AA$ and $\mathrm{C}_{\text {film }}$ is the lattice parameters of analyzing film from XRD results.

\section{G. Electrical Properties}

The electrical properties of the thin film were characterized using 2 point probes I-V measurement system (Keithley 2400). All thin films were deposited with gold ( $\mathrm{Au})$ metal contact for I-V measurement using a sputter coater (EMITECH K550X) with a thickness of $60 \mathrm{~nm}$ and the width of the metal contact about $3.003 \times 10^{-3} \mathrm{~m}$. The metal contacts were deposited at a deposition time of 4 minutes and sputtering current of $50 \mathrm{~mA}$ to achieve the thickness of 60 $\mathrm{nm}$. The parameters for metal contact deposition are listed in Table 3.

TABLE IIIII SPUTTER COATER PARAMETERS

\begin{tabular}{|l|l|}
\hline Metal Target & Gold $(\mathrm{Au})$ \\
\hline Deposition Current & $50 \mathrm{~mA}$ \\
\hline Deposition Time/Thickness & $4 \mathrm{~min} / 60 \mathrm{~nm}$ \\
\hline Deposition Ambient & Argon \\
\hline Sputtering Pressure & $1 \times 10-1 \mathrm{mbar}$ \\
\hline
\end{tabular}

Fig. 6 shows the metal contact patterns on the deposited $\mathrm{ZnO}$ thin films on Teflon substrate. Fig. 7 shows the device structure configurations for $\mathrm{I}-\mathrm{V}$ measurements on the deposited $\mathrm{ZnO}$ thin films where $\mathrm{w}$ is the width, $\mathrm{t}$ is the thickness of the $\mathrm{ZnO}$ thin film and 1 is the length. This configuration is used in order to calculate the electrical resistivity and conductivity of deposited $\mathrm{ZnO}$ thin films on Teflon substrate. The electrical properties of deposited $\mathrm{ZnO}$ thin films were measured by 2 point probes IV measurement system (Keithley 2400).

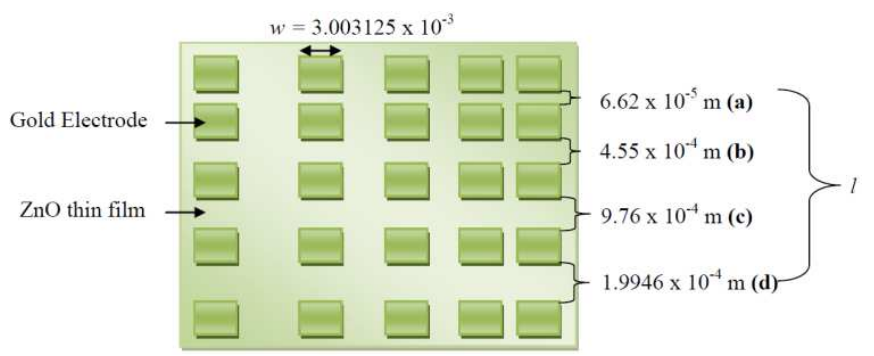

Fig. 6 Metal contact pattern

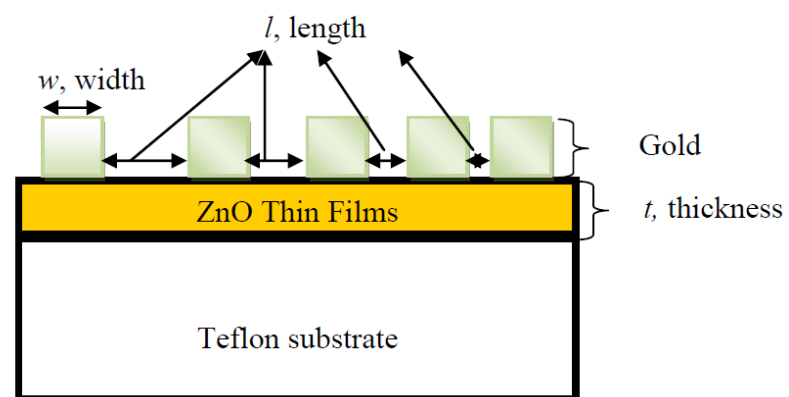

Fig. 7 Device structure configurations for I-V measurement

The thickness of $\mathrm{ZnO}$ thin films was measured using a surface profiler. With the IV data, the electrical resistivity and conductivity can be calculated using equations as follows

$$
\begin{gathered}
\rho=\left(\frac{V}{I}\right)\left(\frac{w t}{x}\right) \\
\sigma=\left(\frac{1}{\rho}\right)
\end{gathered}
$$

where $\rho$ is resistivity, $\mathrm{V}$ is voltage, $\mathrm{I}$ is current, $\mathrm{w}$ is the width of $\mathrm{Au}, \mathrm{t}$ is $\mathrm{ZnO}$ thin film thickness, $\mathrm{x}$ is the distance between electrodes and $\sigma$ is conductivity.

\section{RESULTS AND DISCUSSION}

\section{A. Structural Properties}

Fig. 8 shows the FESEM images of the deposited $\mathrm{ZnO}$ films at different substrate temperatures. All samples show that the deposited thin films consist of nano-sized particles. The sample deposited at room temperature exhibits columnar structured grains with quite relatively large grain size. However, as the substrate temperature was increased from room temperature to $60^{\circ} \mathrm{C}$, the shape of the grains changed. The grains shape changed from columnar to sphere-like shape as can be seen from the FESEM images. The difference of the grain shapes can be attributed to the particles movement that assisted by re-crystalline process which expected to be different according to the substrate temperature, the resistive switching ratio for sample annealed at 120 minutes decreased to 1.1 and the hysteresis loop is thinning to almost becoming an ohmic characteristic but still has the memristive behaviour. This may be due to 
poor interaction of metal and oxide layer as the annealing process increased the surface roughness and grain size [14].

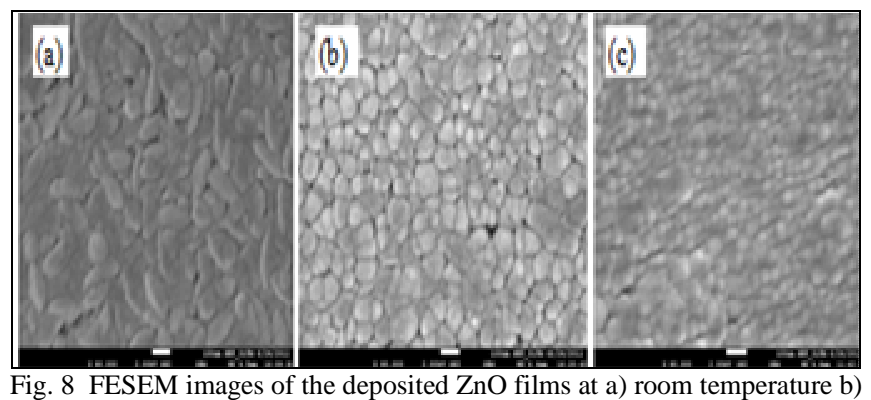
$40^{\circ} \mathrm{C}$ and c) $60^{\circ} \mathrm{C}$

Fig. 9 shows the XRD pattern of deposited $\mathrm{ZnO}$ thin films at different substrate temperatures. It is observed that the deposited thin films at different substrate temperatures exhibits (002) diffraction structure that belongs to the hexagonal wurtzite type of $\mathrm{ZnO}$ (JCPDS \#36-1451) [21], [22]. It illustrated that the (002) diffraction peak for deposited $\mathrm{ZnO}$ thin film at $40^{\circ} \mathrm{C}$ shows the highest peak intensity compared to other thin films, which indicates that the film is strongly c-axis oriented [13], [14]. However, when increased the substrate temperature, the (002) peak tends to decrease. Generally, it is said that higher substrate temperature will improve crystalline quality [15]-[17]. However, in our case, it is different. We predict that as the temperature increases, the Teflon substrate starts to deform. Even though the melting temperature of Teflon is about $\sim 327^{\circ} \mathrm{C}$ and the setting temperature seems low enough not to cause deformation of the Teflon substrate, but during the sputtering process, the plasma temperature and the bombardment of the energetic particles on the substrate may increase the substrate temperature higher than the setting temperature.

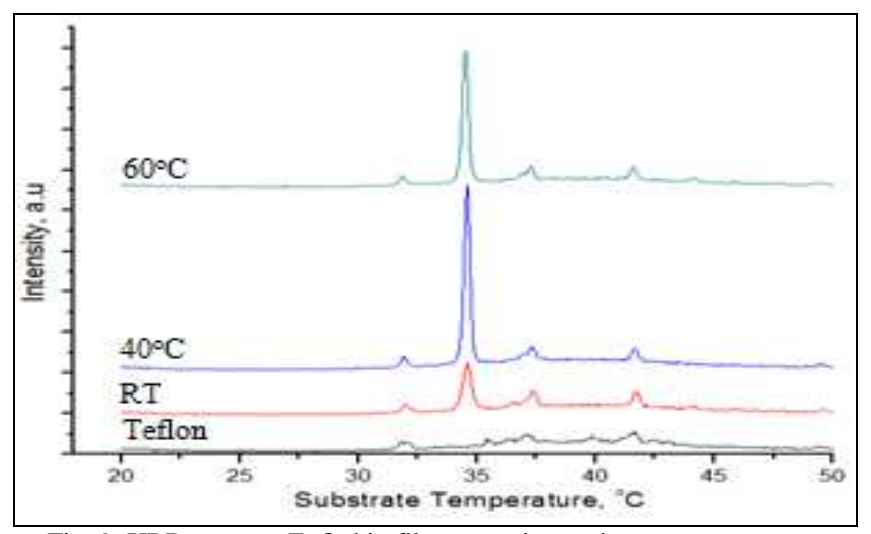

Fig. 9 XRD patterns $\mathrm{ZnO}$ thin films at various substrate temperatures

The full width at half maximum (FWHM) of the (002) peak for all samples was ranged from $0.24^{\circ} \mathrm{C}$ to $0.42^{\circ} \mathrm{C}$. It is observed that the FWHM decreases as the substrate temperature increases, which can be translated into increments of crystallite size as can be seen in Fig. 10.

From the XRD data, the average crystallite sizes for the thin films deposited at room temperature, $40^{\circ} \mathrm{C}$ and $60^{\circ} \mathrm{C}$ were between $21 \mathrm{~nm}$ to $35.2 \mathrm{~nm}$ in which the crystallite size increased with the substrate temperature.

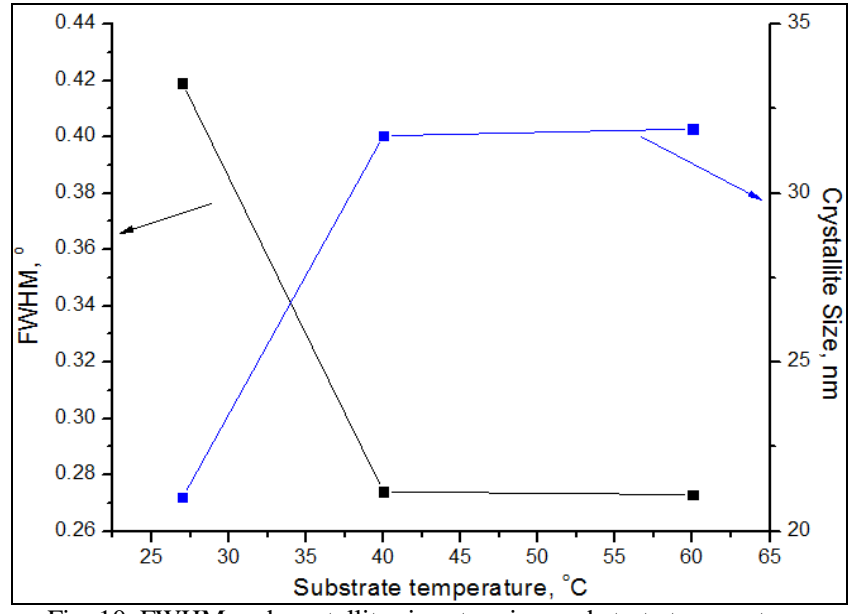

Fig. 10 FWHM and crystallite size at various substrate temperatures

Aside from crystallite size, the stress and strain of the thin films also can be calculated using the obtained XRD data. The calculated of strain and stress values were plotted in Fig. 11 .

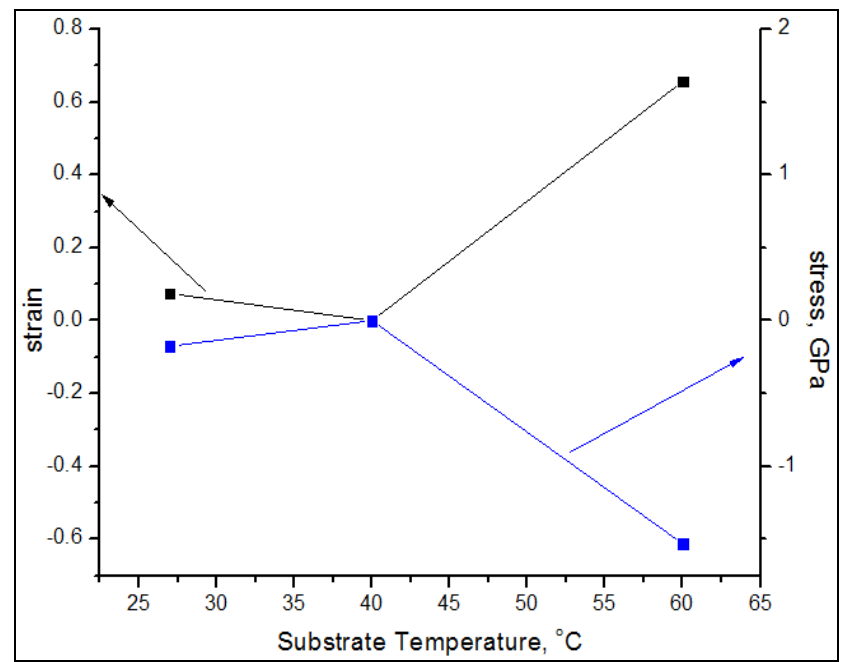

Fig. 11 Strain and stress value at various substrate temperatures

The negative stress denotes that the film is in compression condition and the positive stress denotes the tensile state of the film. Generally, there are two types of stress, which are extrinsic stress and intrinsic stress. Extrinsic stress comes from the difference in the thermal expansion coefficients between the film and the substrate [18]. In this work, Teflon substrate shows high thermal expansion coefficient $\left(135 \times 10^{-}\right.$ $\left.{ }^{6} \mathrm{~K}^{-1}\right)$ and zinc oxide is $\left(4.75 \times 10^{-6} \mathrm{~K}^{-1}\right)$. The literature has been reported that normally the extrinsic stress is in a relaxed state if the thickness is larger [19]. In this work, the extrinsic stress is not present due to the thickness of the thin film is $\sim 500 \mathrm{~nm}$. With this, the sample of $\mathrm{ZnO}$ thin films is totally intrinsic stress in which the intrinsic stress comes from the growth process of ingrown defects or structural mismatch between the film and the substrate [20]. It shows that the strain, $\varepsilon_{\mathrm{zz}}$ in the film is a tensile strength. Meanwhile, the stress in the film is in compressive strength. The expansion and shrinkage of the Teflon substrate during the sputtering process and cooling process are prone to have compressive stress. From the obtained results, it indicates that higher c- 
axis orientation, higher peak intensity (002) will have more relaxed films and better crystalline quality which are at $40^{\circ} \mathrm{C}$.

\section{B. Electrical Properties}

TABLE IVV

Electrical Properties at VARIOUS SubStRate Temperatures

\begin{tabular}{|l|l|l|l|}
\hline $\begin{array}{l}\text { Substrate } \\
\text { Temperature }\end{array}$ & $\begin{array}{l}\text { Thickness } \\
(\mathbf{n m})\end{array}$ & $\begin{array}{l}\text { Conductivity } \\
\left(\mathbf{S m}^{\mathbf{1}} \mathbf{)}\right.\end{array}$ & $\begin{array}{l}\text { Resistivity } \\
(\mathbf{\Omega m})\end{array}$ \\
\hline $27^{\circ} \mathrm{C}$ & 590 & $0.81 \times 10^{-2}$ & $1.24 \times 10^{2}$ \\
\hline $40^{\circ} \mathrm{C}$ & 520 & $4.41 \times 10^{-2}$ & $2.27 \times 10^{1}$ \\
\hline $60^{\circ} \mathrm{C}$ & 690 & $2.98 \times 10^{-2}$ & $3.36 \times 10^{1}$ \\
\hline
\end{tabular}

The current-voltage (I-V) curve of $\mathrm{ZnO}$ thin films deposited at different substrate temperatures was shown in Fig. 12. The results show all the thin films reveal ohmic behavior with $\mathrm{Au}$ metal contact. It can be seen that $\mathrm{ZnO}$ thin film deposited at $40^{\circ} \mathrm{C}$ shows the highest current intensity as the applied voltage changes from $-10 \mathrm{~V}$ to $10 \mathrm{~V}$. However, as the substrate temperature increased from $40^{\circ} \mathrm{C}$ to $60^{\circ} \mathrm{C}$, the current intensity decreased.

The calculated value of the electrical resistivity and conductivity were tabulated in Table 4 and plotted in Fig. 11. It can be seen that the electrical conductivity increases as the substrate temperature increase from room temperature to $40^{\circ} \mathrm{C}$. However, it decreases when the temperature increases to $60^{\circ} \mathrm{C}$. This indicates that $40^{\circ} \mathrm{C}$ is the optimum temperature that would give higher conductivity.

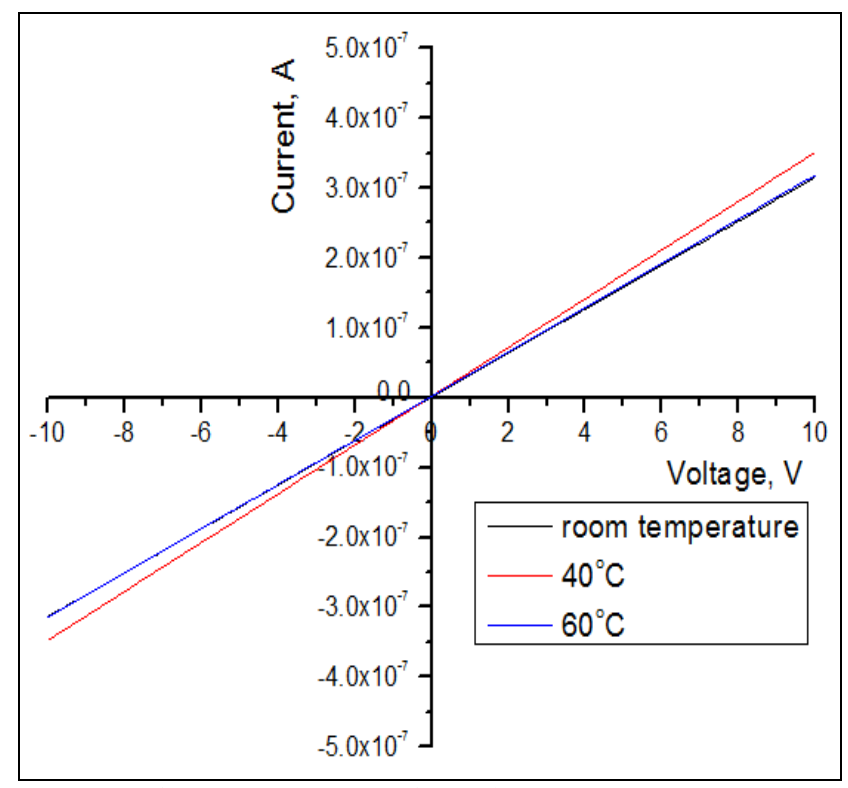

Fig. 12 I-V curve at various substrate temperatures

The electrical resistivity of deposited $\mathrm{ZnO}$ thin film is the inverse of the electrical conductivity. Therefore, the electrical resistivity of the thin films decreases as the substrate temperature increases to $40^{\circ} \mathrm{C}$ and increases with the temperature as can be seen from Fig. 13. This is closely related to the $\mathrm{ZnO}$ thin film crystalline quality characterized by XRD in which the thin film deposited at $40^{\circ} \mathrm{C}$ has the highest crystalline quality. The better crystalline quality of material, the lesser imperfection in the atomic lattice. This imperfection hampers the movement of electrons which can be translated into higher resistivity of the material. This is portrayed by our results where the sample having the best crystalline quality gives the highest conductivity, and when the crystalline quality reduced with increasing the substrate temperature, the conductivity also decreased.

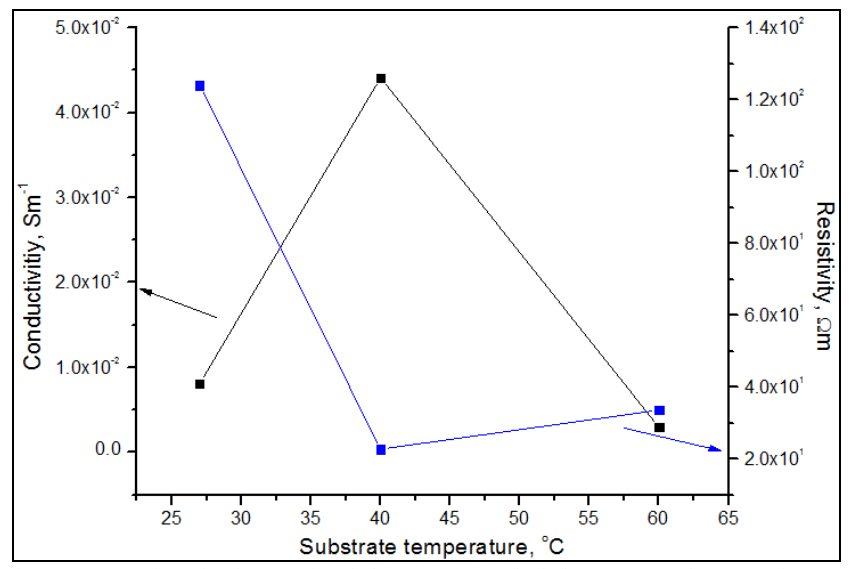

Fig. 13 Electrical conductivity and resistivity at various substrate temperatures

\section{CONCLUSION}

In conclusion, we have demonstrated the growth of $\mathrm{ZnO}$ thin films on Teflon substrate using RF magnetron sputtering method at different substrate temperature. FESEM images show that deposited $\mathrm{ZnO}$ thin films consist of nano-sized particles. From the obtained results, $\mathrm{ZnO}$ thin films deposited at $40^{\circ} \mathrm{C}$ shows highest (002) peak intensity. It can be concluded that with c-axis orientation will have relaxed films and improved electrical properties of $\mathrm{ZnO}$ thin films.

\section{ACKNOWLEDGMENT}

The author likes to express her thanks to Minister of Higher Education (MOHE) for financial support (600RMI/RAGS 5/3 (198/2014)) and also to the Institute of Science Universiti Teknologi MARA for providing the laboratory facilities and technical support.

\section{REFERENCES}

[1] Y. Y. Liu, Y. Z. Yuan, C. F. Li, X. T. Gao, X. Z. Cao, and J. B. Li, "The structure and photoluminescence properties of RF-sputtered Films of $\mathrm{ZnO}$ on Teflon substrate," Materials Letters, vol. 62, pp. 2907-2909, Jun. 2008.

[2] C. Y. Ren, S. H. Chiou, and C. S. Hsue, "Ga-doping effects on electronic and structural properties of wurtzite ZnO," Physica B: Condensed Matter, vol. 349, pp. 136-142, Jun. 2004.

[3] M. G. S. Paz and R. R. Bon, "Indium tin oxide films deposited on polyethylene naphthalate substrates by radio frequency magnetron sputtering," Thin Solid Films, vol. 517, pp. 2596-2601, Feb. 2009.

[4] H. Liu and C. Lei, "Low-temperature deposited titanium-doped zinc oxide thin films on the flexible PET substrate by DC magnetron sputtering," Vacuum, vol. 86, pp. 483-486, Nov. 2011.

[5] L. Gong, J. Lu, and Z. Ye, "Transparent and conductive ga-doped $\mathrm{ZnO}$ films grown by RF magnetron sputtering on polycarbonate substrates," Solar Energy Materials and Solar Cells, vol. 94, pp. 937941, Jun. 2010.

[6] Y. C. Lin, M. Z. Chen, C. C. Kuo, and W. T. Yen, "Electrical and optical properties of $\mathrm{ZnO}$ : $\mathrm{Al}$ film prepared on polyethersulfone substrate by RF magnetron sputtering," Colloids and Surfaces A: Physicochemical and Engineering Aspects, vol. 337, pp. 52-56, Apr. 2009.

[7] Y. Y. Liu, Y. Z. Yuan, X. T. Gao, S. S. Yan, X. Z. Cao, and G. X. Wei, "Deposition of $\mathrm{ZnO}$ thin film on polytetrafluoroethylene substrate by magnetron sputtering method," Materials Letters, vol. 61, pp. 4463, Sep. 2007. 
[8] A. Fridman, Plasma Chemistry, 1st ed., Cambridge, England: Cambridge University Press, 2008.

[9] S. Lyon, "Materials selection for corrosion control," International Materials Reviews, vol. 40, pp. 135-136, Jul. 2013.

[10] Y. Hu, O. K. Tan, J. S. Pan, H. Huang, and W. Cao, "The effects of annealing temperature on the sensing properties of low temperature nano-sized $\mathrm{SrTiO}_{3}$ oxygen gas sensor," Sensors and Actuators B: Chemical, vol. 108, pp. 244-249, Jul. 2005.

[11] B. Huang, G. He, and H. Yang, "Effects of annealing on excitonic properties of sputtered $\mathrm{ZnO}$ films at room temperature," Journal of Optoelectronics and Advanced Materials, vol. 12, pp. 2369-2372, 2010.

[12] H. Y. Liu, G. S. Tang, F. Zeng, and F. Pan, "Influence of sputtering parameters on structures and residual stress of Aln films deposited by DC reactive magnetron sputtering at room temperature," Journal of Crystal Growth, vol. 363, pp. 80-85, Jan. 2013

[13] X. Ding and Y. Lai, "Electrical and optical properties of zinc oxide thin films deposited by magnetron sputtering," ECS Transactions, vol. 34, pp. 577-582, Mar. 2011

[14] J. J. Kim, J. H. Lee, J. Y. Lee, D. J. Lee, B. R. Jang, and H. S. Kim, "Characteristics of $\mathrm{ZnO}$ films deposited on plastic substrate at various RF sputtering powers," Journal of Korean Physical Society, vol. 55, pp. 1910-1914, Nov. 2009.

[15] J. H. Park, J. M. Shin, S. Cha, J. W. Park, S. Jeong, H. K. Pak, and C. Cho, "Deposition-temperature effects on AZO thin films prepared by RF magnetron sputtering and their physical properties," Journal of the Korean Physical Society, vol. 49, pp. S584-S588, Dec. 2006.

[16] R. Ondo-Ndong, H. Z. Moussambi, H. Gnanga, A. Giani, and A. Foucaran, "Optical properties of $\mathrm{ZnO}$ thin films deposed by $\mathrm{RF}$ magnetron," International Journal of Physical Sciences, vol. 10, pp.173-181, Mar. 2015.

[17] K. S. Kim, H. W. Kim, and N. H. Kim, "Structural characterization of $\mathrm{ZnO}$ films grown on $\mathrm{SiO}_{2}$ by the RF magnetron sputtering," Physica B: Condensed Matter, vol. 334, pp. 343-346, Jul. 2003.

[18] R. S. Sreedharan, V. Ganesan, C. P. Sudarsanakumar, K. Bhavsar, R. Prabhu, and V.P.P.M. Pillai, "Highly textured and transparent RF sputtered $\mathrm{Eu}_{2} \mathrm{O}_{3}$ doped $\mathrm{ZnO}$ films," Nano Reviews, vol. 6, pp. 1-16, Mar. 2015.

[19] A. K. Kalita and S. Karmakar, "Effect on particle size and microstrain due to iron doping on $\mathrm{ZnO}$ nanoparticle prepared by wet chemical method," International Journal of Scientific Research, vol. 5, pp. 654-655, Apr. 2016.

[20] S. Kunj and K. Sreenivas, "Residual stress and defect content in magnetron sputtered $\mathrm{ZnO}$ films grown on unheated glass substrates," Current Applied Physics, vol. 16, pp. 748-756, Jul. 2016.

[21] I. M. Yassin, A. Zabidi, M. S. A. M. Ali, N. M. Tahir, H. A. Hassan, H. Z. Abidin, and Z. I. Rizman, "Binary particle swarm optimization structure selection of nonlinear autoregressive moving average with exogenous inputs (NARMAX) model of a flexible robot arm," International Journal on Advanced Science, Engineering and Information Technology, vol. 6, pp. 630-637, Oct. 2016.

[22] M. N. M. Nor, R. Jailani, N. M. Tahir, I. M. Yassin, Z. I. Rizman, and R. Hidayat, "EMG signals analysis of $\mathrm{BF}$ and RF muscles in autism spectrum disorder (ASD) during walking," International Journal on Advanced Science, Engineering and Information Technology, vol. 6, pp. 793-798, Oct. 2016. 